\title{
Correction to: How life cycle-based science and practice support the transition towards a sustainable economy
}

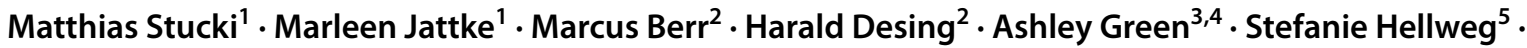 \\ Rafael Laurenti ${ }^{6} \cdot$ Ronny Meglin $^{7} \cdot$ Karen Muir $^{1} \cdot$ Dario Pedolin $^{3,8} \cdot$ Rhythima Shinde $^{5} \cdot$ Tobias Welz $^{9}$. \\ Regula Lisa Keller ${ }^{1}$
}

Published online: 4 January 2022

(c) The Author(s) 2022

\section{Correction to: The International Journal of Life Cycle Assessment https://doi.org/10.1007/s11367-021-01894-1}

The original version of this article unfortunately contained mistakes in co-authors affiliations.

Co-Author Dario Pedolin's affiliation is:

3 Agroscope, Research Group Life-Cycle Assessment, Zürich, Switzerland

8 Department of Environmental Systems Science, Institute of Agricultural Sciences, ETH Zürich, Zürich, Switzerland

Co-Author Ronny Megilin's affiliation is:

7 University of Applied Sciences of Eastern Switzerland, Rapperswil, Switzerland

The original article has been corrected.
Open Access This article is licensed under a Creative Commons Attribution 4.0 International License, which permits use, sharing, adaptation, distribution and reproduction in any medium or format, as long as you give appropriate credit to the original author(s) and the source, provide a link to the Creative Commons licence, and indicate if changes were made. The images or other third party material in this article are included in the article's Creative Commons licence, unless indicated otherwise in a credit line to the material. If material is not included in the article's Creative Commons licence and your intended use is not permitted by statutory regulation or exceeds the permitted use, you will need to obtain permission directly from the copyright holder. To view a copy of this licence, visit http://creativecommons.org/licenses/by/4.0/.

Publisher's Note Springer Nature remains neutral with regard to jurisdictional claims in published maps and institutional affiliations.

The original article can be found online at https://doi.org/10.1007/ s11367-021-01894-1.

Matthias Stucki

stucki@zhaw.ch

1 Institute of Natural Resource Sciences, Zurich University of Applied Sciences (ZHAW), Wädenswil, Switzerland

2 Technology and Society Lab, Empa - Swiss Federal Laboratories for Material Science and Technology, St. Gallen, Switzerland

3 Agroscope, Research Group Life-Cycle Assessment, Zürich, Switzerland

4 Department of Health Sciences and Technology, Institute of FoodNutrition and Health, ETH Zürich, Zürich, Switzerland
5 Department of Civil, Environmental and Geomatic Engineering, Institute of EnvironmentalEngineering, ETH Zürich, Zürich, Switzerland

6 Department of Machine Design, KTH Royal Institute of Technology, Stockholm, Sweden

7 University of Applied Sciences of Eastern Switzerland, Rapperswil, Switzerland

8 Department of Environmental Systems Science, Institute of Agricultural Sciences, ETH Zürich, Zürich, Switzerland

9 Research Centre for Digital Sustainability, University of Berne, Berne, Switzerland 